\title{
Microwave-assisted synthesis of silver nanoparticles and their application in catalytic, antibacterial and antioxidant activities
}

\author{
Kondaiah Seku ${ }^{1} \cdot$ Bhagavanth Reddy Gangapuram ${ }^{2} \cdot$ Babu Pejjai $^{3} \cdot$ Kishore Kumar Kadimpati $^{4} \cdot$ Narasimha Golla $^{5}$
}

Received: 2 February 2018 / Accepted: 20 May 2018 / Published online: 8 June 2018

(c) The Author(s) 2018

\begin{abstract}
Eco-friendly silver nanoparticles (AgNPs) were synthesized using a carboxymethylated gum kondagogu (CMGK) as capping and reducing agent by microwave irradiation method. Synthesized AgNPs were analyzed by TEM, showed spherical in shape with an average particle size distribution of $9 \pm 2 \mathrm{~nm}$. XRD results showed that the cubic-structured AgNPs with crystallite size of $8.6 \mathrm{~nm}$. The synthesized CMGK capped AgNPs was tested for catalytic activity using hexacyanoferrate(III) in the presence of $\mathrm{NaBH}_{4}$ and the impacts of catalyst dose and temperature were examined. The synthesized AgNPs demonstrated a huge antibacterial action on both Gram-positive and negative groups of microorganisms with inhibition zone of 23, 25 and $28 \mathrm{~mm}$, respectively, for Bacillus subtilis, Bacillus cereus and Escherichia coli, they showed moderate antibacterial action (zone of inhibition $15 \mathrm{~mm}$ ) with Pseudomonas aeruginosa. In addition, the ability of the AgNPs scavenging activity with different concentrations was studied using the DPPH radical scavenging.
\end{abstract}

Keywords Microwave irradiation $\cdot$ Silver nanoparticles $\cdot$ Antibacterial $\cdot$ Antioxidant $\cdot$ Catalytic activities

Kondaiah Seku

kondareddyseku@gmail.com

Bhagavanth Reddy Gangapuram

bhagavanth.g@gmail.com

Babu Pejjai

pdmj.babu@gmail.com

Kishore Kumar Kadimpati

drkadimpatikks@gmail.com

Narasimha Golla

gnsimha@svuniversity.ac.in

1 Department of Chemistry, Shinas College of Technology, Shinas, Sultanate of Oman

2 Department of Chemistry, Palamuru University, Mahbubnagar, Telangana, India

3 Information Materials Laboratory (IMSL), School of Chemical Engineering, Yeungnam University, Gyeongsam, Republic of Korea

4 Department of Pharmaceutics, Narayana Pharmacy College, Nellore, Andhra Pradesh, India

5 Department of Engineering (Applied Science-Chemistry), Shinas College of Technology, Shinas, Sultanate of Oman

\section{Introduction}

Nanotechnology has the ability to recommend solutions to the society in diverse fields $[1,2]$ such as sustainable production of chemicals, water treatment, and medicine, solar energy conversion, etc. [2,3]. Researchers have great interest towards the green-production of metal nanoparticles owing to their inimitable characteristics and extensive aptness in a various field like chemistry, physics, biomedical science and material science $[4,5]$. The metal nanoparticles showing notable physical, optical, chemical and thermal properties [6], which might be owing to the combination of the nanometer scale and a substantial proportion of high energy surface atoms relative to the bulk solid, mean free path of an electron changing its conductivity and mobility [7-9]. Particularly, silver nanoparticles (AgNPs) show significant applications in bio imaging, catalysis, colorimetric sensors, drug delivery, surface-enhanced Raman scattering, etc. [10-13]. The AgNPs in the colloidal state have widely been used to research the catalytic action in the model reaction is electron exchange reaction between hexacyanoferrate(III) to hexacyanoferrate(II) $[14,15]$. Antibacterial agents have importantly benefited the health-related quality of human life towards fighting with bacterial infections [14, 16-18]. AgNPs has been used for antibacterial agent incident times, due to smaller size, low toxicity easily synthesize. 
Antioxidants play a role in the oxidative process of aging in human and animals $[19,20]$.

Several methods are reported $[1,4,7]$ for AgNPs synthesis, among them, most conventional and comfortable method is the reduction of the metal salt solution by means of reducing agents like $N, N$-dimethyl form amide, when the above chemicals used as reducing agent, it causes environmental toxicity or hazards. Alternatively, researchers are interested towards the green synthesis of AgNPs to avoid the negative impact on the environment $[21,22]$. AgNPs synthesis using polysaccharides [14-16, 23-28] is an alternative resolution for the aforementioned complications. The synthesis of AgNPs by different plant parts such as leaf, fruit, bark, latex, stem, gums and various biological systems has been reported $[16,17$, 19, 29-32]. Although the synthesis of AgNPs using polysaccharides has some disadvantages, it needs more time for the synthesis. Similarly, the as-synthesized AgNPs showed lower catalytic and biological activity. To activate the AgNPs, carboxymethylation is one of the systems utilized for the functionalization of natural polymers [33]. Carboxymethylation in general expands the hydrophilicity and solution clearness of the polysaccharides and improves it dissolvable in an aqueous system. It is a broadly utilized alteration technique in light of its simplicity of handling, bring down cost of chemicals and versatility of the product obtained. Many natural gums such as Cassia tora gum, gellan, guar gum, and gum karaya were investigated using the carboxymethylation process [34-37].

Gum kondagogu (Cochlospermum gossypium) is a chemically polysaccharide component, naturally abundantly available, cheap, non-toxic, biodegradable, eco-friendly [15-17]. Further, it has potential applications in various fields. The essential structure of gum kondagogu comprised poly saccharides with linkage, i.e., $(1 \rightarrow 6) \beta$-D-Gal p, $(1 \rightarrow 4) \beta$-D-Glc p, 4-O-Me- $\alpha$-D-Glc p, $(1 \rightarrow 2) \alpha$-L-Rha and $(1 \rightarrow 2) \beta$-D-Gal p.

Synthesis of AgNPs using carboxymethylation gum kondagogu enhances the stability of nanoparticles, as well as the as-synthesized AgNPs showed good catalytic and biological activities. In this research investigation, a modified gum (carboxymethylated gum kondagogu) was utilized for the development of AgNPs, and the AgNPs were characterized by UV, FTIR, XRD and TEM. The as-synthesized AgNPs examined for potential catalytic, antioxidant and antibacterial activities. The antimicrobial action of the AgNPs was inspected using Gram-negative and Gram-positive bacterial strains.

\section{Materials and methods}

\section{Materials and chemicals}

Purchased gum kondagogu from Girijan Cooperative Society Corporation, Telangana, India. $\mathrm{AgNO}_{3}$ was purchased from the Sigma-Aldrich. Potassium hexacyanoferrate(III), monochloroacetic acid; sodium borohydride, sodium hydroxide, nitric acid, and hydrochloric acid were purchased from Merck. Agar-agar, tryptophan bacterial grade and yeast extract were acquired from Hi Media Laboratories, Mumbai, India. Purchased all test strains from IMTECH, Chandigarh, India. All the chemicals utilized were of analytical grade.

\section{Preparation of gum solution}

One gram of gum kondagogu was dissolved in $200 \mathrm{ml}$ of distilled water and this was stirred for $5 \mathrm{~h}$ at room temperature. This gum solution was centrifuged to remove the insoluble materials and later the supernatant was lyophilized and used for analysis. The lyophilized gum powder was used for further process.

\section{Synthesis of carboxymethyl gum kondagogu}

The carboxymethyl gum kondagogu was synthesized using the previously described method adapted from [38] with slight modifications [15, 39-44]. In the typical preparation, first, $0.5 \mathrm{~g}$ of gum kondagogu powder was dispersed in $40 \mathrm{ml}$ of ice-cold $\mathrm{NaOH}(40 \%$, w/w) with the aid of $60 \mathrm{~min}$, and $5 \mathrm{ml}$ of monochloroacetic acid $(60 \% \mathrm{w} / \mathrm{v})$ was added to the reaction mixture over a period of $10 \mathrm{~min}$ under constant stirring. The whole mixture was heated to $75^{\circ} \mathrm{C}$ and stirred for $60 \mathrm{~min}$. After the reaction, mixture was cooled naturally. Then it suspended into an $80 \%(\mathrm{v} / \mathrm{v})$ methanol, a precipitate was obtained, which was filtered out. The precipitate was neutralized using glacial acetic acid. The precipitate was washed three times with $50 \mathrm{ml}$ of $80 \%(\mathrm{v} / \mathrm{v})$ methanol, sifted and dried in a hot air oven at $45{ }^{\circ} \mathrm{C}$.

\section{Synthesis of silver nanoparticles}

All glassware utilized were washed with water regia (3:1 $\mathrm{HCl}-\mathrm{HNO}_{3}$ ) and afterward thoroughly flushed with twofold refined water. All the working solutions were prepared with double distilled water. The CMGK solution $(5 \mathrm{ml})$ was mixed with $2 \mathrm{ml}$ of $\mathrm{AgNO}_{3}(0.5 \%)$ solution in a bubbling tube and the blend was subjected to microwave irradiation for $50-90 \mathrm{~s}$ at $750 \mathrm{~W}$ power. The subsequent solution was of yellowish-orange in color, evidence of the development of AgNPs. After formation, the AgNPs were centrifuged at 20,000 rpm for $30 \mathrm{~min}$ and then the filtrate was re-dispersed in Milli-Q water. The centrifugation and scattering process were repeated twice to expel any unreacted $\mathrm{AgNO}_{3}$ and CMGK solution from the end product. 


\section{Characterization of AgNPs}

The developed CGMK capped AgNPs were characterized by UV-Vis spectrophotometer (UV-3600, Schimadzu) in the wavelength range of 200-700 $\mathrm{nm}$ against the blank gum solution as a reference. The FTIR (JASCO, Model FT/IR-4600/4700) studies were performed to appraise the functional groups of CMGK potentially associated with the reduction and stabilization of synthesized NPs. The crystallinity of CMGK capped AgNPs was considered by XRD (Rigaku, Miniflex) strategy with $\operatorname{Cuk}_{\alpha}(\lambda=1.5418 \AA$ ) radiation). The morphology and size dispersion of the CMGK capped AgNPs dispersion was studied by TEM. TECNAI G2 F20 S-TWIN instrument was used for recording TEM images.

\section{Catalytic activity}

The formed AgNPs potential catalytic activity was examined utilizing an electron exchange reaction between hexacyanoferrate(III) and $\mathrm{NaBH}_{4}$. The reaction methodology was as per the following; $0.7 \mathrm{ml}$ of $10 \mathrm{mM}$ hexacyanoferrate(III), freshly prepared $1.3 \mathrm{ml}$ of $36 \mathrm{mM}$ $\mathrm{NaBH}_{4}$ in $0.1 \mathrm{M} \mathrm{NaOH}$ solution were mixed with $1 \mathrm{ml}$ of Milli-Q water and the reaction mixture was transferred into a $5 \mathrm{ml}$ quartz cuvette. To this mixture, varying concentrations of (50-250 $\mu \mathrm{l})$ of AgNPs solutions were added. Thus, the absorbance intensity of ferric cyanide for the initial reaction was recorded at $420 \mathrm{~nm}$. After the addition of AgNPs, the intensity decrease was monitored using UV-Vis spectrophotometer. The electron transfer reaction was performed at different temperatures between 30 and $70{ }^{\circ} \mathrm{C}[36,45]$.

\section{Antibacterial studies}

The synthesized silver nanoparticles were tried for antibacterial action by agar well diffusion technique against the following microorganism, i.e., Pseudomonas aeruginosa, Escherichia coli, Bacillus cereus and Bacillus subtilis. The formation of clearing zones was measured in $\mathrm{mm}$ using the ruler scale method and compared with standard Streptomycin (positive control). In brief, $100 \mu \mathrm{l}$ of a log phase cultures were seeded in the nutrient agar medium (beef extract, peptone and agar) for bacteria's. After solidification of all agars Petri plates $8 \mathrm{~mm}$ diameter five wells were formed by punching with sterile borer. In four wells $100 \mu$ of various concentrations of AgNPs samples (0.2, 0.4, 0.6 and $0.8 \mu \mathrm{g} /$ $\mathrm{ml})$ and in one well streptomycin $(400 \mu \mathrm{g} / \mathrm{ml})$ as positive control were loaded. At $37^{\circ} \mathrm{C}$ in incubator the petri plates were incubated for $24 \mathrm{~h}$. The experiment was performed in triplicate for each pathogenic bacterium's and compared with the standard. Zone of inhibitions was measured by means of ruler method.

\section{Antioxidant activity}

The antioxidant activity for green synthesized AgNPs was evaluated using DPPH assay. This assay was followed by formerly reported method with few modifications [28]. Different volumes $(3,7,10,15,20$, and $25 \mu \mathrm{l})$ of AgNPs is made up to $60 \mu \mathrm{l}$ with dimethyl sulfoxide and $205 \mathrm{ml}$ DPPH $(0.15 \mathrm{mM})$ solution was added. The above mixture was shaken vigorously and kept in the black paper (dark) for $40 \mathrm{~min}$ at room temperature. The absorbance was recorded at $517 \mathrm{~nm}$ against a blank of DPPH and ascorbic acid was used as Ref. [19]. The free radical scavenging activity was estimated using the following expression:

DPPH scavenging effect $(\%)=\frac{A_{0}-A_{\mathrm{t}}}{A_{0}} \times 100$,

$A_{0}$ is the absorbance of the control and $A_{\mathrm{t}}$ is the absorbance of the sample.

\section{Results and discussion}

\section{UV-visible spectroscopy}

Electronic spectroscopy is one of the simplest methods to characterize AgNPs. AgNPs show a strong absorption band due to surface plasmon resonance in the visible region at 415-430 nm. The development of AgNPs were easily identified by alter in shade of the reaction blend from light yellow to dark yellow. In request to contemplate the impact of CMGK concentration on the development of AgNPs, different trails were performed out by varying the amount of CMGK from 0.1 to $0.5 \%$ keeping the concentration of $\mathrm{AgNO}_{3}$ at constant. The corresponding changes in the SPR peak are shown in Fig. 1a. With the increase of CMGK concentration from 0.1 to 0.5 , the SPR peak intensity was increased due the decrease of particle size. This indicates that increased CMGK concentration could increase the formation of AgNPs by reducing more $\mathrm{Ag}+$ ions. Similarly, it controlled the size of AgNPs by effectively capping the nanoparticles. We also examined the effect of concentration of $\mathrm{AgNO}_{3}$ for the synthesis of $\mathrm{AgNPs}$ by keeping the concentration of CMGK $(0.5 \%)$ constant. Figure $1 \mathrm{~b}$ clearly suggested that with increase of $\mathrm{AgNO}_{3}$ concentration, more and more number of $\mathrm{Ag}^{+}$ions become available in the solution, which further reduced and effectively capped by CMGK molecules to produce more number of AgNPs [36, 39, 46, 47].

\section{FTIR analysis of AgNPs}

CMGK and CMGK-stabilized AgNPs were recorded by FTIR spectrophotometer (Fig. 2). The major peaks [curve (a) of Fig. 2] in the IR spectrum of CMGK peaks were observed at 3430, 2960, 1733, 1615, 1415, 1225, 

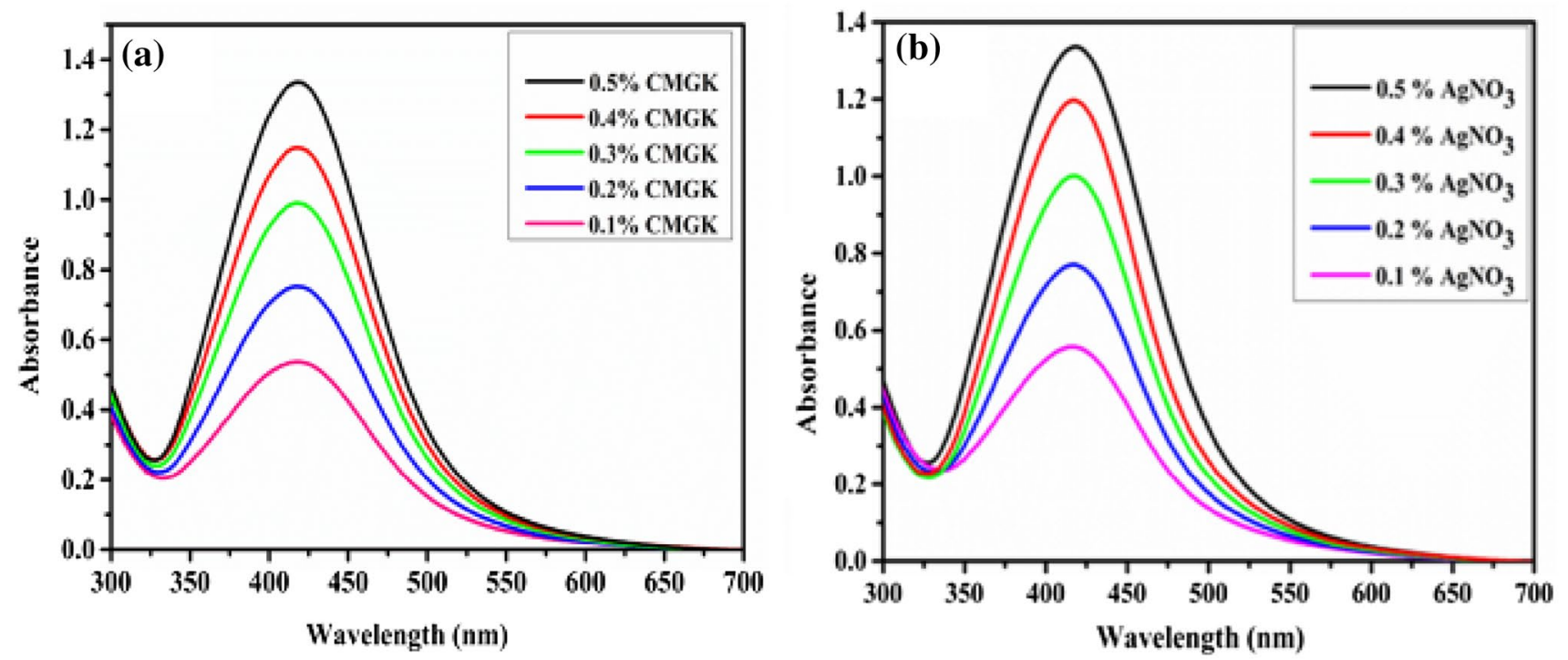

Fig. 1 UV-visible spectra of synthesized AgNPs; a at different concentrations of CMGK solution at $0.5 \% \mathrm{AgNO}_{3}$ and $\mathbf{b}$ at different concentrations of $\mathrm{AgNO}_{3}$ with $0.5 \%$ CMGK

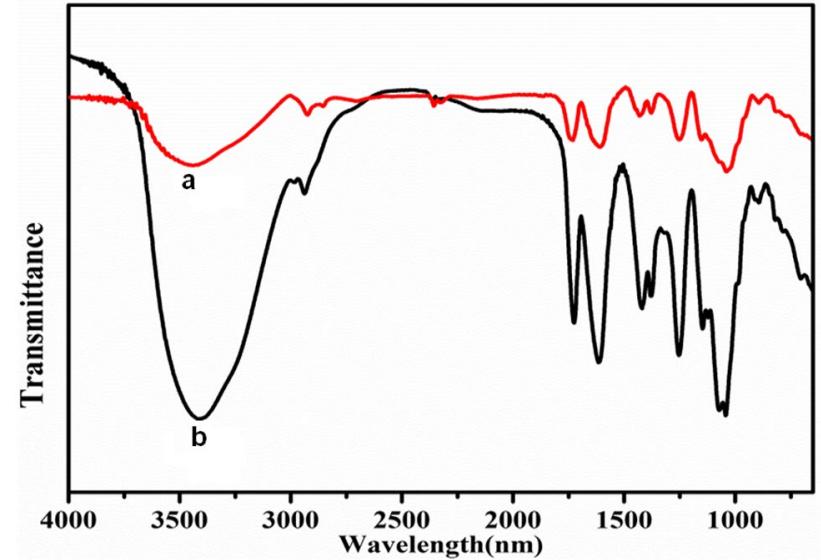

Fig. 2 FTIR spectra: (a) CMGK and (b) CMGK-capped AgNPs

and $1035 \mathrm{~cm}^{-1}$. The peaks at 3430 and $2960 \mathrm{~cm}^{-1}$ are assigned to stretching vibrations related to $\mathrm{O}-\mathrm{H}$ and $\mathrm{C}-\mathrm{H}$ groups. The other strong peaks observed at 1733, 1615 and $1416 \mathrm{~cm}^{-1}$ could be attributed to characteristic asymmetrical and symmetrical stretching vibrations of the $\mathrm{CO}_{2}^{-}$(carboxylation) group. The peaks at 1225 and $1035 \mathrm{~cm}^{-1}$ are associated with the $\mathrm{C}-\mathrm{O}-\mathrm{C}$ stretching vibrations of ether and alcohol groups of CMGK. Figure 2(curve b) shows the FTIR spectrum of CMGK-capped AgNPs. This FTIR spectrum shows the characteristic frequencies at 3375 , $1727,1591,1406,1220$, and $1026 \mathrm{~cm}^{-1}$. The shifts in the peaks of the CMGK-capped AgNPs FTIR spectrum were watched from 3430 to $3375,1733-1727,1615-1591$, $1415-1410 \mathrm{~cm}^{-1}$ and other peaks observed were to remain unchanged. These shifts in the IR spectrum suggested that the linking of AgNPs with hydroxyl and carboxylate groups of carboxymethylated gum kondagogu. The peak shifts in the hydroxyl and carboxyl groups, it can be presumed that both hydroxyl and carbonyl groups of CMGK are involved $[15,24,35,47]$ in the synthesis and stabilization of AgNPs.

\section{XRD analysis}

Figure 3a shows the XRD criterion of the developed AgNPs. The characteristic diffraction peaks were observed at $2 \theta$ values at $38.32,44.50,64.75$ and 77.05 , which were indexed to (111), (201), (222), and (312), planes of silver, respectively. In XRD pattern, all the peaks were readily indexed to a face-centered cubic structure of silver (JCPDS, File No. 04-0783) [48]. From Fig. 3a, the (111) peak is the most intense compared to the other peaks in the spectrum, which indicates the preferred growth of AgNPs along (111) direction [25-27, 49]. The calculated lattice constant was observed to be $a=0.4085 \mathrm{~nm}$, which is consistent with the standard value of $a=0.4086 \mathrm{~nm}$. The synthesized AgNPs crystalline size was calculated using Scherer's formula:

$D=\frac{0.9 \lambda}{\beta \cos \theta}$,

where $D$ is the crystalline size, $\beta$ is the full width at half maximum, $\lambda$ is the wavelength of $X$-ray used $(1.5406 \AA)$ and $\theta$ is the Bragg's angle. The crystallite size was calculated to be $8.6 \mathrm{~nm}$, which is in good agreement with the TEM results. 


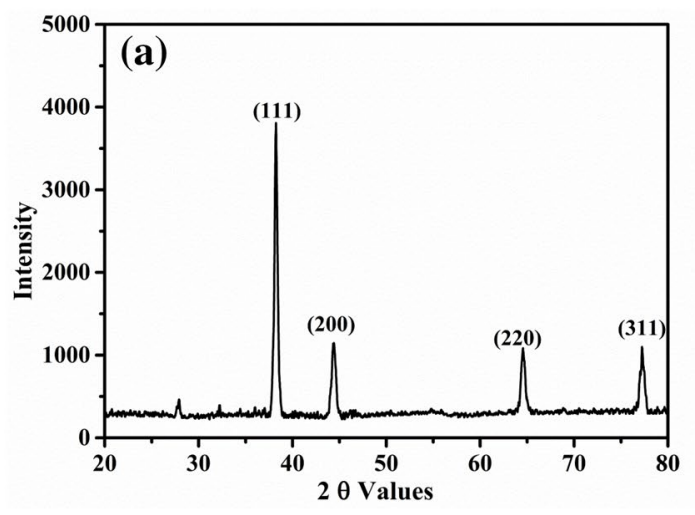

Fig. 3 a XRD pattern of AgNPs and b SAED patterns of AgNPs

\section{TEM studies}

The TEM pictures of the synthesized AgNPs are shown in Fig. 4a. Synthesized silver nanoparticles have spherical shape with smooth surface and well dispersed. The resultant AgNPs completely revealed that the CMGK can protect silver nanoparticles from aggregation efficiently. The histogram (Fig. 4b) was developed by considering 100 AgNPs, it clearly recommends that the mean size dispersion of AgNPs is $9 \pm 2 \mathrm{~nm}$. The corresponding SAED criterion is shown in Fig. 3b. A clear and uniform lattice fringes are showed by AgNPs, which confirmed that the spherical AgNPs particles have highly crystalline nature [16, 28]. Lattice space of $0.232 \mathrm{~nm}$ corresponds to (111) plane of silver, which indicates that the preferred face of AgNPs is along (111).

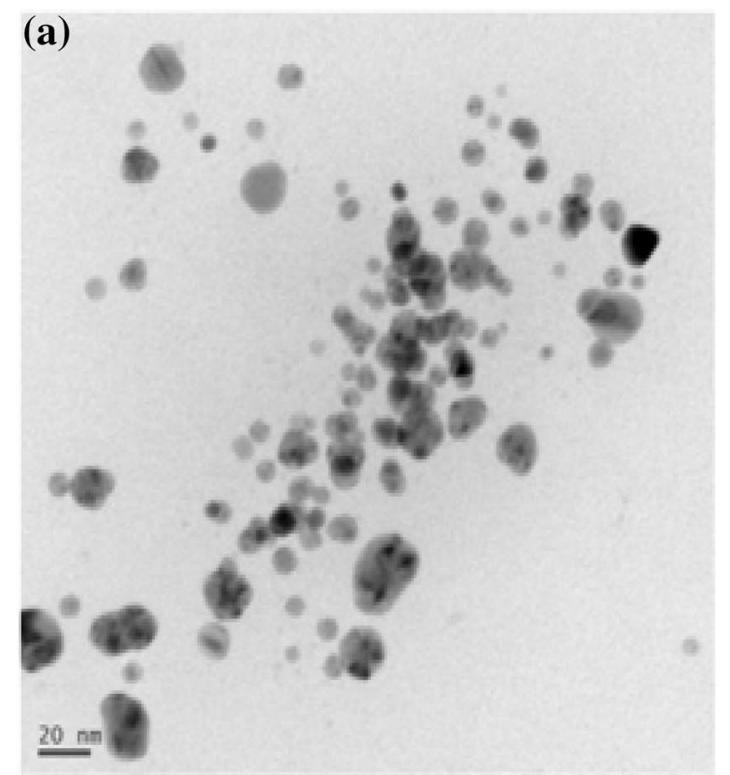

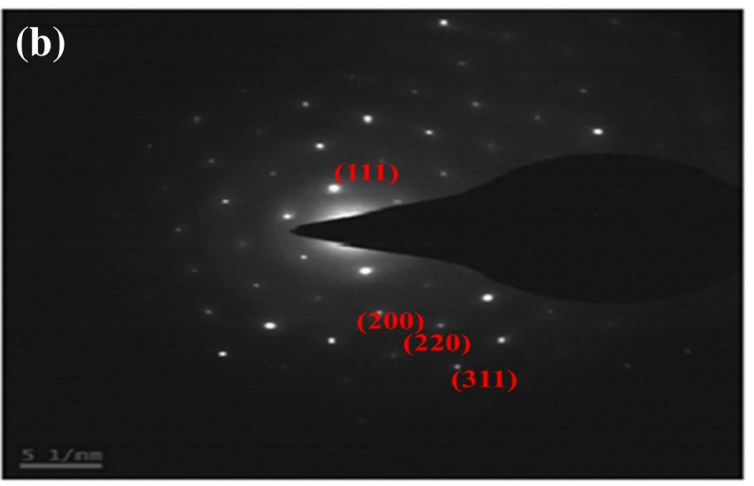

\section{Stability of AgNPs}

The stability of AgNPs in solution is an essential prerequisite for their chemical and biological applications. Stability of synthesized CMGK-capped AgNPs was studied by monitoring the SPR peak and zeta potential. In Fig. 5, under neutral conditions, the AgNPs exhibited a zeta potential value of $-18.7 \mathrm{mV}$, which indicates the surface of AgNPs is covered with negatively charged groups like hydroxyl and carboxyl groups. Therefore, the AgNPs are highly stable due to the strong electrostatic repulsions between the particles.

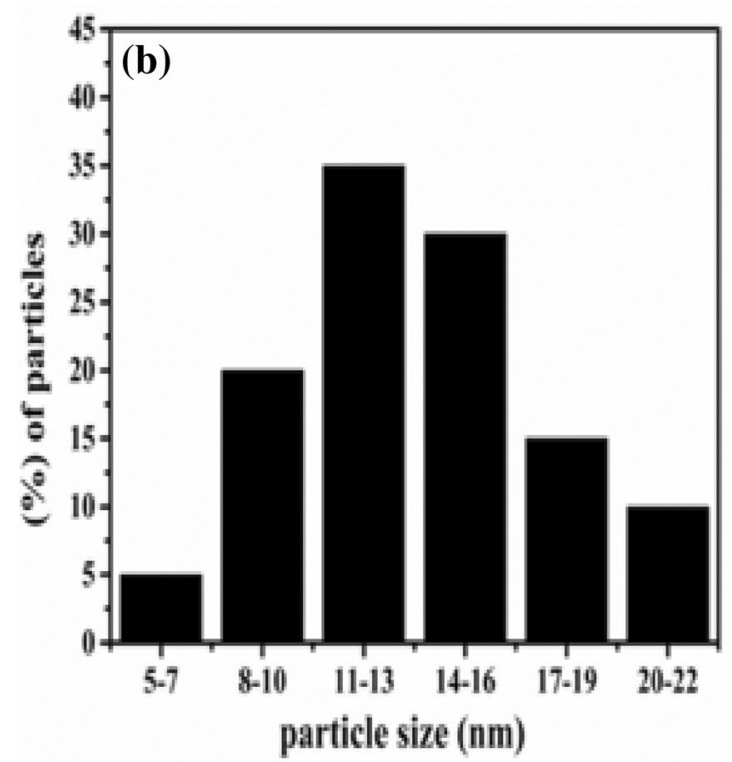

Fig. 4 a TEM image of synthesized AgNPs with $0.5 \%$ (w/v) CMGK and $0.5 \% \mathrm{AgNO}_{3}$ and $\mathbf{b}$ the particle size distribution histogram of $\mathrm{AgNPs}$ 


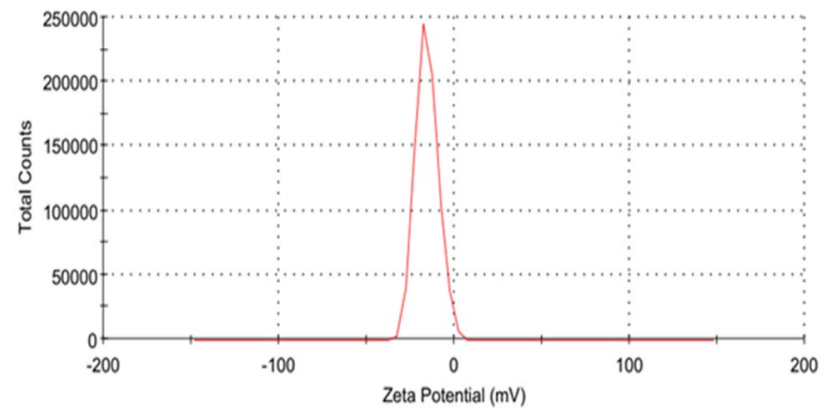

Fig. 5 Zeta potential of synthesized AgNPs

\section{Proposed mechanism involved in the development of AgNPs}

In this work, we have utilized CMGK as a reducing and stabilizing specialist for the development of AgNPs. The method which was totally nontoxic, low cost and ecofriendly. The primary structure of CMGK is made up of polysaccharides, which contains the carbonyl and hydroxyl groups in abundance. The large number of carbonyl and hydroxyl groups helps in the complexation of $\mathrm{Ag}^{+}$ions. These $\mathrm{Ag}^{+}$ions oxidize the hydroxyl to carbonyl groups, during which the $\mathrm{Ag}^{+}$ions are reduced to elemental $\mathrm{Ag}$. In this oxidation, the dissolved air is also a source of oxidation of the hydroxyl groups to carbonyl groups such as carboxylates and aldehydes.

\section{Catalytic reduction of hexacyanoferrate(III)}

The silver nanoparticles were used as a catalytic in the electron exchange reaction between hexacyanoferrate(III) and sodium borohydride, bringing about the arrangement of hexacyanoferrate(II) ions and dihydrogen borate ions. The redox reaction is described as:

$\left[\mathrm{BH}_{4}\right]^{-}+8\left[\mathrm{Fe}(\mathrm{CN})_{6}\right]^{-3} 3 \mathrm{H}_{2} \mathrm{O} \longrightarrow \mathrm{H}_{2} \mathrm{BO}_{3}^{-}+8\left[\mathrm{Fe}(\mathrm{CN})_{6}\right]^{-4}+8 \mathrm{H}^{+}$.

The advantage of hexacyanoferrate ion for this redox study is that oxidation states of iron $(+2$ and +3$)$ are quite stable with reference to dissociation and hydrolysis. The redox potential corresponding to the reaction being studied, $E_{\mathrm{o}}\left(\mathrm{Fe}^{2+/} \mathrm{Fe}^{3+}\right)$ is $+0.44 \mathrm{~V}$ versus a normal hydrogen electrode. The standard reduction potential of the borate ion is $E_{\mathrm{o}}=-1.24 \mathrm{~V}$. Hence, there is a huge free energy change associated with the reaction $[14,15]$. Notwithstanding, this reaction even though advance without a catalyst, however, it is accounted as moderate reaction with zero-order kinetics.

The progress of the reduced reaction of Potassium hexacyanoferrate(III) to Potassium hexacyanoferrate(II) was monitored during changes in the UV-visible spectrum. The characteristic absorption peak of hexacyanoferrate(III) was observed at $420 \mathrm{~nm}$. By addition of nanoparticles, the magnitude of the absorption point was continuously decreased with time revealing the occurrence of catalyzed reduction (Fig. 6). The redox reaction is a pseudo first-order reaction with respect to hexacyanoferrate(III) [45]. As the centralization of $\mathrm{NaBH}_{4}$ was more noteworthy than the hexacyanoferrate(III), the reduction rate can be thought to be autonomous of $\mathrm{NaBH}_{4}$ quantity. The kinetics of reduction reaction of the hexacyanoferrate(III) catalyzed by AgNPs were investigated at different temperatures $\left(30-70{ }^{\circ} \mathrm{C}\right)$ and different amounts of catalyst. The reaction was carried out keeping all experimental conditions such as initial concentration of hexacyanoferrate(III), borohydride concentration and temperature at constant.

The rate constants were calculated by differing the amount of AgNPs (50-250 $\mu \mathrm{l}$ ). Rate constant values (Table 1) were plotted against different quantities of catalyst as appeared in Fig. 7a. The response rate is found to increment straightly with the expansion in the measure of AgNPs, because of an improvement in the quantity of reaction surface sites. There is a linear relationship between the observed rate constant and the amount of catalyst.

The rate constant of catalytic reaction was studied at different temperatures $\left(33,42,51,62\right.$ and $\left.73{ }^{\circ} \mathrm{C}\right)$ and at fixed concentrations of hexacyanoferrate(III), borohydride and

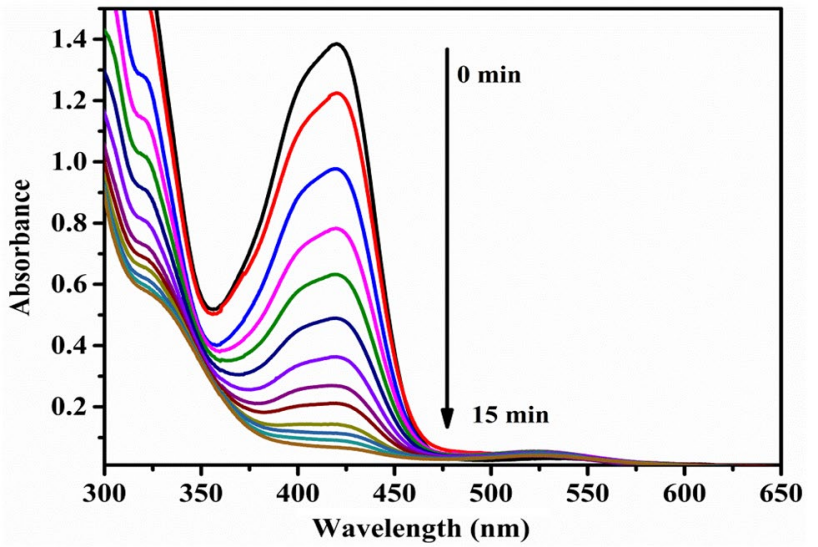

Fig. 6 Time dependent UV-Vis spectra of hexacyanoferrate(III) and sodium borohydride mixture upon addition of AgNPs

Table 1 Rate constants at different amount of catalyst

\begin{tabular}{lll}
\hline sample & Amount of $\operatorname{AgNPs}(\mu \mathrm{L})$ & $\begin{array}{l}\text { Calculated rate } \\
\text { constant }\left(\mathrm{min}^{-1}\right)\end{array}$ \\
\hline 1 & 50 & 0.0721 \\
2 & 100 & 0.123 \\
3 & 150 & 0.164 \\
4 & 200 & 0.210 \\
5 & 250 & 0.252 \\
\hline
\end{tabular}



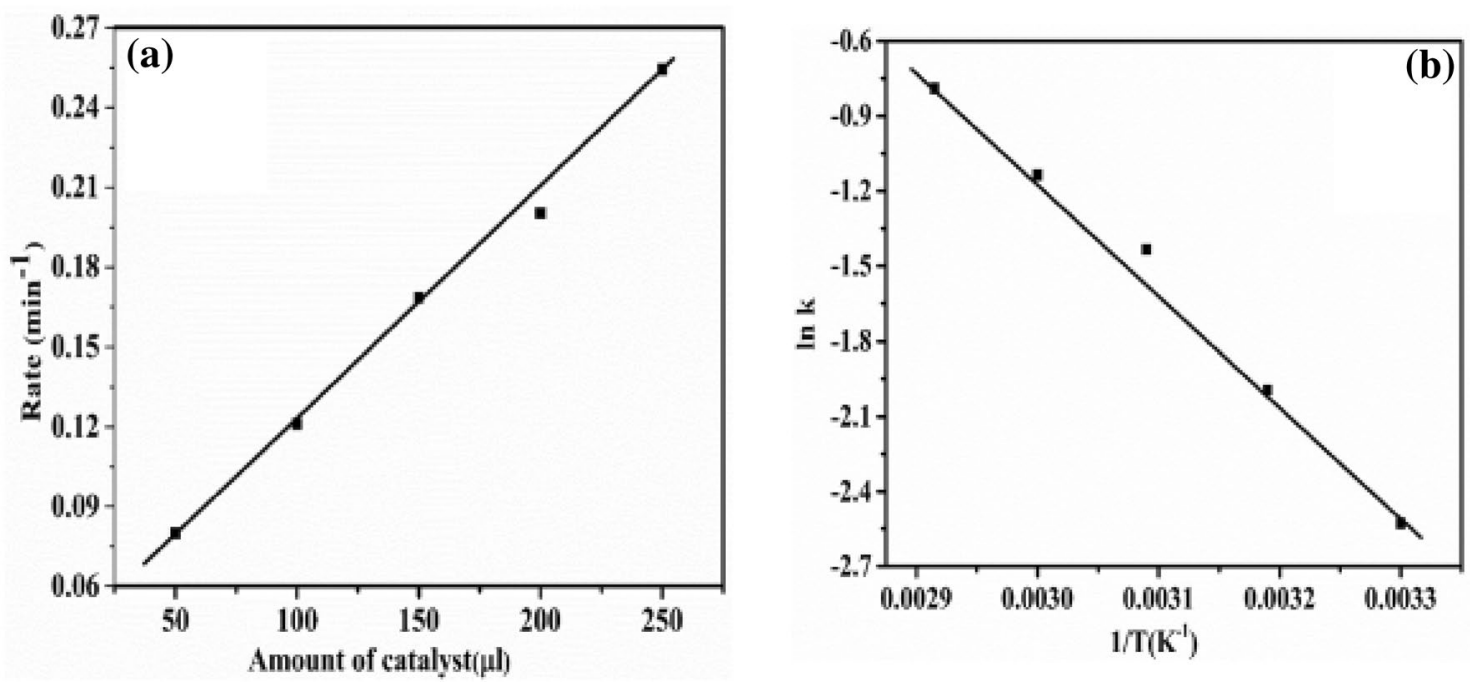

Fig. 7 a Plot of rate constant against different amounts of silver nanoparticles and b plot of rate constant against $1 / T\left(\mathrm{~K}^{-1}\right)$ for the electron transfer reaction between hexacyanoferrate(III) and sodium borohydride in the presence of AgNPs

Table 2 Rate constants at different temperatures for AgNPs catalyzed reduction of hexacyanoferrate(III) by $\mathrm{NaBH} 4$

\begin{tabular}{ll}
\hline Temperature (K) & $\begin{array}{l}\text { Rate } \\
\text { constant } \\
\left(\mathrm{min}^{-1}\right)\end{array}$ \\
\hline 303 & 0.0761 \\
313 & 0.174 \\
323 & 0.242 \\
333 & 0.305 \\
343 & 0.415 \\
\hline
\end{tabular}

amount of catalyst. The Arrhenius plot of $\ln k$ versus $1 / T$ is given in Fig. 7b. The activation energy was figured from the slope $\left(-E_{\mathrm{a}} / R\right)$. It is watched that the increase in temperature expands the rate of reaction (Table 2 ). The activation energy was computed from the $\left(-E_{\mathrm{a}} / R\right)$ of the straight line and was observed to be $7.2 \mathrm{kcal} / \mathrm{mol}$.

\section{Antibacterial action of AgNPs}

Antibacterial action of CMGK-capped silver nanoparticles was tested against Gram-negative ( $P$. aeruginosa and $E$. coli) and Gram-positive (B. subtilis and B. cereus) bacterial strains and showed in Fig. 8 (Table 3). The outcomes demonstrated that the as-synthesized AgNPs have discrete antibacterial action against pathogenic microorganisms $[14,16,25,27]$ at $5 \mu \mathrm{g} / \mathrm{ml}$ concentration. The AgNPs were contrasted positively with silver nitrate, CMGK and standard antibiotic, streptomycin at concentration of $5 \mu \mathrm{g} / \mathrm{ml}$. The AgNPs revealed more action than silver nitrate and standard antibiotic, but CMGK solution does not show zone of inhibition. AgNPs were genuinely lethal to $B$. cereus, B. subtilis, and E. coli with inhibition zone of 25 ,
28 and $23 \mathrm{~mm}$. The AgNPs indicated great antibacterial action against $E$. coli, $B$. cereus and $B$. subtilis and furthermore, less activity against $P$. aeruginosa. All the bacteria's showed increasing activity by increasing concentration of AgNPs. It can be inferred that the blended AgNPs demonstrated noteworthy antibacterial activity on both gram classes of microorganisms [17, 18, 50].

\section{Anti-oxidation studies}

The antioxidant activity of the synthesized AgNPs is evaluated using DPPH assay using ascorbic acid as reference. This assay is a simple and less expensive. The antioxidant activity of synthesized AgNPs was assessed in terms of percentage inhibition of DPPH radicals in the presence of ascorbic acid. The DPPH is considered more stable nitrogen-centered free radical due to exhibiting a higher degree of accepting hydrogen atoms or electrons from antioxidant materials [19]. The DPPH solution color change was observed on the addition of AgNPs, which is due to the scavenging action of DPPH by addition of hydrogen to form the yellow-colored DPPH. Figure 9 shows the inhibition activity of AgNPs in comparison to the ascorbic acid (standard) and it is observed that the DPPH radical inhibition activity was enhanced with the quantity of silver nanoparticles. At concentration 5, 10, 15, 20, 25 and $30 \mu 1$ shows a scavenging rate 20.5, 46.2, 57.4, 61.7, 63.6 and $64.9 \%$, respectively. When compared to ascorbic acid, the AgNPs shows enhanced activity. The better quenching rate of DPPH radicals shows greater anti-oxidation ability of the obtained AgNPs [18, 20]. 

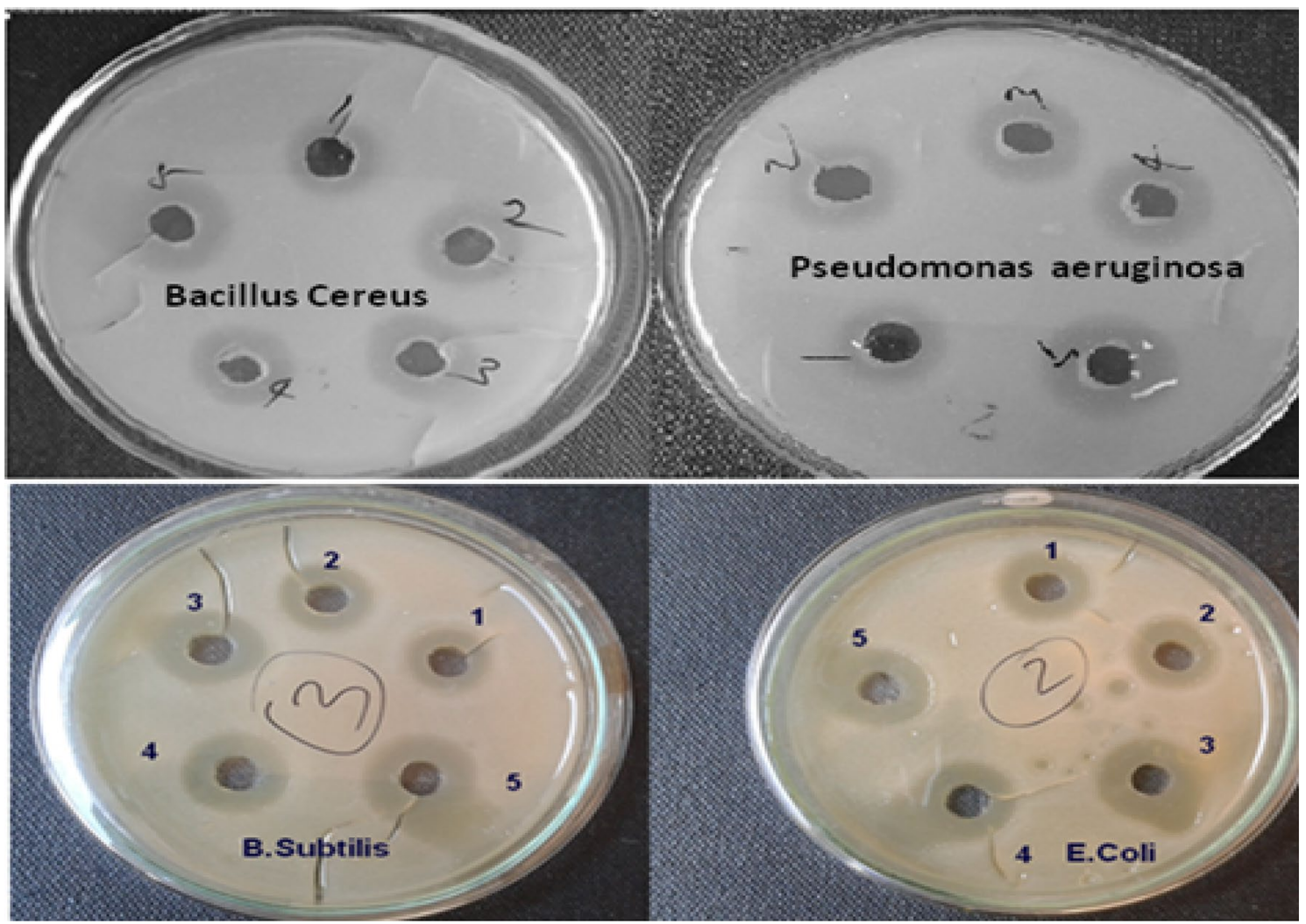

Fig. 8 Antibacterial activity of CMGK capped silver nano particles using Bacillus cereus, Bacillus subtilis, Escherichia coli, Pseudomonas aeruginosa $(1 \mathrm{mg} / \mathrm{ml}$ solution: discs containing $(1)=10 \mu \mathrm{l}$

Table 3 Antibacterial activities of AgNPs at different concentrations (zone of inhibition in $\mathrm{mm}$ )

\begin{tabular}{lllll}
\hline Organism & \multicolumn{4}{l}{$\begin{array}{l}\text { Zone of inhibition } \\
\text { concentrations }\end{array}$} \\
\cline { 2 - 5 } & 20 & 40 & 60 & 80 \\
\hline Streptomycin & 17 & 20 & 22 & 24 \\
Bacillus subtilis & 18 & 19 & 21 & 23 \\
Bacillus cereus & 14 & 18 & 20 & 25 \\
Pseudomonas aeruginosa & 10 & 12 & 14 & 15 \\
Escherichia coli & 18 & 21 & 25 & 28 \\
\hline
\end{tabular}

\section{Conclusion}

The synthesis was completed in an aqueous medium by a microwave irradiation method using CMGK. The results of XRD showed that highly crystalline face-centered cubic structure to AgNPs. TEM analysis indicated that the synthesized AgNPs were spherical in shape with an average size distribution of $9 \pm 2 \mathrm{~nm}$. The catalytic activity application of green-synthesized AgNPs was examined by the reduction of potassium hexacyanoferrate(III) to potassium of gum solution, (2)=10 $\mu \mathrm{l}$ of AgNPs, (3)=20 $\mu \mathrm{l}$ of AgNPs, (4) $=30 \mu \mathrm{l}$ of AgNPs, (5) $=10 \mu \mathrm{l}$ of ampicillin)

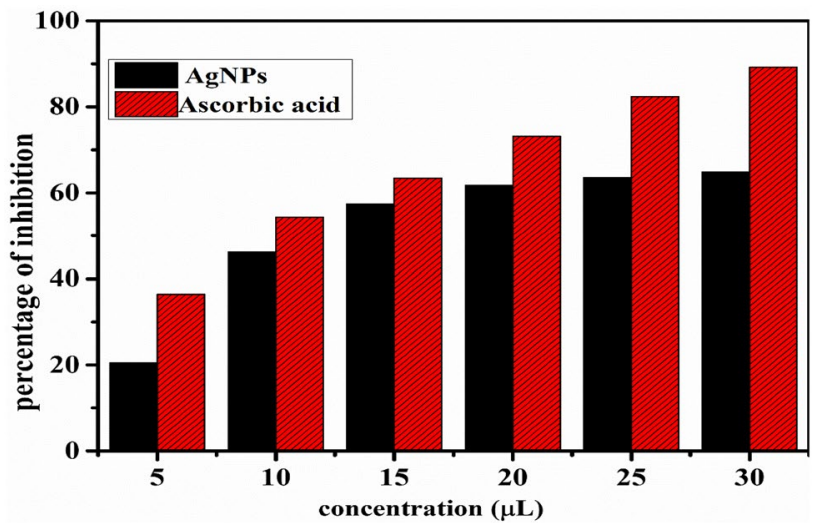

Fig. 9 Figure exhibiting free radical scavenging activity of AgNPs through DPPH assay

hexacyanoferrate(II) and activation energy was found to be $7.2 \mathrm{kcal} / \mathrm{mol}$. The synthesized AgNPs showed good antibacterial activity with inhibition zone of 28,25 and $23 \mathrm{~mm}$, respectively, for E. coli, B. cereus and B. subtilis, whereas it showed moderate antibacterial activity (zone of inhibition $15 \mathrm{~mm}$ ) with $P$. aeruginosa. The prepared AgNPs have excellent antioxidant characteristics against 
DPPH assay. Our study indicates that the CMGK-capped AgNPs showed significant catalytic activity, antibacterial and antioxidant activity, which suggest their possible application in pharmaceutical industry.

Acknowledgments The first author would like to thanks to UGC, New Delhi, India for the financial support from UGC Minor Research Project Grant (Sanction letter: No: F.MRP -6210/15(SERO/UGC). The author thanks the Principal and Management of Malla Reddy Engineering College (Autonomous) for providing research facilities.

\section{Compliance with ethical standards}

Competing interest The authors declare that they have no competing interests.

Open Access This article is distributed under the terms of the Creative Commons Attribution 4.0 International License (http://creativeco mmons.org/licenses/by/4.0/), which permits unrestricted use, distribution, and reproduction in any medium, provided you give appropriate credit to the original author(s) and the source, provide a link to the Creative Commons license, and indicate if changes were made.

\section{References}

1. Eustis, S., Sayed, M.: Why gold nanoparticles are more precious than pretty gold: noble metal surface plasmon resonance and its enhancement of the radiative and nonradioactive properties of nanocrystals of different shapes. Chem. Soc. Rev. 35, 209-217 (2006)

2. Dreaden, E.C., Alkilany, A.M., Huang, X., Murphy, C.J., ElSayed, M.: The golden age: gold nanoparticles for biomedicine. Chem. Soc. Rev. 41, 2740-2764 (2012)

3. Jans, H., Huo, Q.: Gold nanoparticle-enabled biological and chemical detection and analysis. Chem. Soc. Rev. 41, 2849-2866 (2012)

4. Guo, S., Wang, E.: Synthesis and electrochemical applications of gold nanoparticles. Anal. Chim. Acta 598, 181-192 (2007)

5. Dykman, L., Khlebtsov, N.: Gold nanoparticles in biomedical applications: recent advances and perspectives to biological and medical. Chem. Soc. Rev. 41, 2256-2282 (2012)

6. Hartland, G.V.: Optical studies of dynamics in noble metal nanostructures. Chem. Rev. 111, 3858-3887 (2011)

7. Rodrı, L., Rodríguez-Sánchez, L., Blanco, M.C., Ferracin, L.C.: Electrochemical synthesis of silver nanoparticles. J. Phys. Chem. B. 104, 9683-9688 (2000)

8. Hammond, J.L., Bhalla, N., Rafiee, S.D., Estrela, P.: Localized surface plasmon resonance as a biosensing platform for developing countries. Biosensors. 4, 172-188 (2014)

9. Gangula, A., Podila, R., Karanam, R.M.L., Janardhana, C., Rao, A.M.: Catalytic reduction of 4-nitrophenol using biogenic gold and silver nanoparticles derived from Breynia rhamnoides. Langmuir 27, 15268-15274 (2011)

10. Jain, P.K., Huang, X., El-Sayed, I.H., El-Sayed, M.A.: Noble metals on the nanoscale: optical and photothermal properties and some applications in imaging, sensing, biology, and medicine. Acc. Chem. Res. 41, 7-9 (2008)

11. Joy Prabu, H., Johnson, I.: Plant-mediated biosynthesis and characterization of silver nanoparticles by leaf extracts of Tragia involucrata, Cymbopogon citronella, Solanum verbascifolium and Tylophora ovata. Karbala Int. J. Mod. Sci. 1, 237-246 (2015)

12. Benakashani, F., Allafchian, A.R., Jalali, S.A.H.: Biosynthesis of silver nanoparticles using Capparis spinosa L. leaf extract and their antibacterial activity. Karbala Int. J. Mod. Sci. 2, 251-258 (2016)

13. Rastogi, L., Sashidhar, R.B., Karunasagar, D., Arunachalam, J.: Gum kondagogu reduced/stabilized silver nanoparticles as direct colorimetric sensor for the sensitive detection of $\mathrm{Hg}^{2+}$ in aqueous system. Talanta 118, 111-117 (2014)

14. Hossam, E.E., Hanan, M.K., Zahran, A.B.: Generation of biocompatible nanogold using $\mathrm{H}_{2} \mathrm{O}_{2}$-starch and their catalytic/ antimicrobial activities. Eur. Polym. J. 90, 354-367 (2017)

15. Hossam, E.E., El-Zawahry, M.M., Hanan, A.B.: One-pot fabrication of AgNPs, AuNPs and $\mathrm{Ag}-\mathrm{Au}$ nano-alloy using cellulosic solid support for catalytic reduction application. Carbohydr. Polym. 166, 1-13 (2017)

16. Hanan, A.B., Abdel-Mohsen, A.M., Hossam, E.E.: Greenassisted tool for nanogold synthesis based on alginate as a biological macromolecule. RSC Adv. 6, 73974-73985 (2016)

17. Ruíz-Baltazar, Á.D.J., Reyes-López, S.Y., Larrañaga, D., Estévez, M.: Green synthesis of silver nanoparticles using a Melissa officinalis leaf extract with antibacterial properties. Results Phys. 7, 2639-2643 (2017)

18. Kora, A.J., Sashidhar, R.B.: Antibacterial activity of biogenic silver nanoparticles synthesized with gum ghatti and gum olibanum: a comparative study. J. Antibiot. 68, 88-97 (2015)

19. Mohanta, Y.K., Panda, S.K., Jayabalan, R., Sharma, N.: Antimicrobial, antioxidant and cytotoxic activity of silver nanoparticles synthesized by leaf extract of Erythrina suberosa (Roxb.). Front. Mol. Biosci. 4, 1-9 (2017)

20. Rajan, A., Rajan, A.R., Philip, D.: Elettaria cardamomum seed mediated rapid synthesis of gold nanoparticles and its biological activities. OpenNano. 2, 1-8 (2017)

21. Shon, Y.-S., Cutler, E.: Aqueous synthesis of alkanethiolateprotected ag nanoparticles using bunte salts. Langmuir 20, 6626-6630 (2004)

22. Jana, N.R., Peng, X.: Single-phase and gram-scale routes toward nearly monodisperse au and other noble metal nanocrystals. J. Am. Chem. Soc. 125, 14280-14281 (2003)

23. Zahran, M.K., Hanan, A.B., El-Rafie, M.H.: Alginate mediate for synthesis controllable sized AgNPs. Carbohydr. Polym. 111, 10-17 (2014)

24. Hossam, E.E., Hanan, A.B.: Polysaccharides templates for assembly of nanosilver. Carbohydr. Polym. 135, 300-307 (2016)

25. Hossam, E.E., Zahran, M.K.: Ago nanoparticles containing cotton fabric: synthesis, characterization, color data and antibacterial action. Int. J. Boil. Macromol. 75, 106-114 (2015)

26. Hossam, E.E., El-Bisi, M.K.: Merely Ag nanoparticles using different cellulose fibers as removable reductant. Cellulose 21, 4219-4230 (2014)

27. Hossam, E.E., El-Rafie, M.H., Hanan, A.B., Zahran, M.K.: Room temperature synthesis of metallic nanosilver using acacia to impart durable biocidal effect on cotton fabrics. Fiber Polym. 16, 1676-1687 (2015)

28. Hanan, A.B., Zahran, M.K., Hossam, E.E.: Heatless synthesis of well dispersible $\mathrm{Au}$ nanoparticles using pectin biopolymer. Int. J. Boil. Macromol. 91, 208-219 (2016)

29. Fatimah, I.: Green synthesis of silver nanoparticles using extract of Parkiaspeciosa Hassk pods assisted by microwave irradiation. J. Adv. Res. 7, 961-969 (2016)

30. Ahmed, S., Ahmad, M., Swami, B.L., Ikram, S.: Review on plants extract mediated synthesis of silver nanoparticles for antimicrobial applications: a green expertise. J. Adv. Res. 7, 17-28 (2016) 
31. El-Rafie, M.H., Mohamed, A.A., Shaheen, T.I., Hebeish, A.: Antimicrobial effect of silver nanoparticles produced by fungal process on cotton fabrics. Carbohydr. Polym. 108, 779-782 (2010)

32. Zahran, M.K., Hanan, A.B., El-Rafie, M.H.: Facile size-regulated synthesis of silver nanoparticles using pectin. Carbohydr. Polym. 111, 971-978 (2014)

33. Vinod, V.T.P., Saravanan, P., Sreedhar, B., Devi, D.K., Sashidhar, R.B.: A facile synthesis and characterization of Ag, $\mathrm{Au}$ and Pt nanoparticles using a natural hydrocolloid gum kondagogu (Cochlospermum gossypium). Colloids Surf. B. Biointerfaces. 83, 291-298 (2011)

34. Kumar, A., Ahuja, M.: Carboxymethyl gum kondagogu: synthesis, characterization and evaluation as mucoadhesive polymer. Carbohydr. Polym. 90, 637-643 (2012)

35. Bandi, R.: Facile green synthesis of gold nanoparticles with carboxymethyl gum karaya, selective and sensitive colorimetric detection of copper(II) ions. J. Clust. Sci. 28, 2873-2890 (2017)

36. Reddy, G.B., Madhusudhan, A., Ramakrishna, D., Ayodhya, D., Venkatesham, M., Veerabhadram, G.: Green chemistry approach for the synthesis of gold nanoparticles with gum kondagogu: characterization, catalytic and antibacterial activity. J. Nanostruct. Chem. 5, 185-193 (2015). https://doi.org/10.1007/s4009 7-015-0149-y

37. Vinod, V.T.P., Sashidhar, R.B., Suresh, K.I., Rao, B.R.: Morphological, physico-chemical and structural characterization of gum kondagogu (Cochlospermum gossypium): a tree gum from India. Food Hydrocoll. 22, 899-915 (2008)

38. Ahuja, M., Singh, S., Kumar, A.: Evaluation of carboxymethyl gellan gum as a mucoadhesive polymer. Int. J. Biol. Macromol. 53, 114-121 (2013)

39. Dodi, G., Hritcu, D., Popa, M.I.: Carboxymethylation of guar gum: synthesis and characterization. Cell. Chem. Technol. 45, 171-176 (2011)

40. Hossam, E.E., Salwa, M., Hamada, M., Mashaly, M.R.: Production of antibacterial colored viscose fibers using in situ prepared spherical Ag nanoparticles. Carbohydr. Polym. 110, 148-155 (2014)

41. Hossam, E.E., Manian, A.P., Široká, B., Duelli, H., Merschak, P., Redl, B., Bechtold, T.: Copper(I) oxide surface modified cellulose fibers-synthesis, characterization and antimicrobial properties. Surf. Coat. Technol. 254, 344-351 (2014)
42. Hossam, E.E., Saleh, N.H., Nagy, K.S., Zahran, M.K.: Instantly AgNPs deposition through facile solventless technique for polyfunctional cotton fabrics. Int. J. Biol. Macromol. 84, 308-318 (2016)

43. Hossam, E.E.: Green technology for durable finishing of viscose fibers via self-formation of AuNPs. Int. J. Biol. Macromol. 96, 697-705 (2016)

44. Hossam, E.E., Ahmed, H.B., Bechtold, T.: In-situ deposition of $\mathrm{Cu}_{2} \mathrm{O}$ micro-needles for biologically active textiles and their release properties. Carbohydr. Polym. 165, 255-265 (2017)

45. Reddy, G.B., Ramakrishna, D., Madhusudhan, A., Ayodhya, D., Venkatesham, M., Veerabhadram, G.: Catalytic reduction of $p$-nitrophenol and hexacyanoferrate(III) by borohydride using green synthesized gold nanoparticles. J. Chin. Chem. Soc. 62, 420-428 (2015)

46. Sadanand P, Fosso-Kankeu E, Ramontja J.: Efficient and rapid adsorption characteristics of templating xanthan gum-graftpoly(aniline) and silica nanocomposite toward removal of toxic methylene blue dyes. In: 9th International Conference on Advances in Science, Engineering, Technology \& Waste Management (ASETWM-17) Nov. 27-28, 2017, Parys, South Africa

47. Sadanand, P.: A comprehensive review on recent developments in bentonite based materials used as adsorbents for wastewater treatment. J. Mol. Liquids. 241, 1091-1113 (2017)

48. Hong Kun, H.E., Chao, G.A.O.: Graphene nanosheets decorated with $\mathrm{Pd}, \mathrm{Pt}, \mathrm{Au}$, and $\mathrm{Ag}$ nanoparticles: synthesis, characterization. Sci. Chin. Chem. 54, 397-404 (2011)

49. Sadanand, P., Karuna, Kar N.: An Au nanocomposite based chemiresistive ammonia sensor for health monitoring. ACS Sens. 1, 55-62 (2016)

50. Sadanand, P., James, R.: Sodium alginate stabilized silver nanoparticles-silica nanohybrid and their antibacterial characteristics. Int. J. Biol. Macromol. 93, 712-723 (2016)

Publisher's Note Springer Nature remains neutral with regard to jurisdictional claims in published maps and institutional affiliations. 